\title{
Challenges in reporting on predetermined objectives to the Auditor-General: The case of Limpopo provincial departments
}

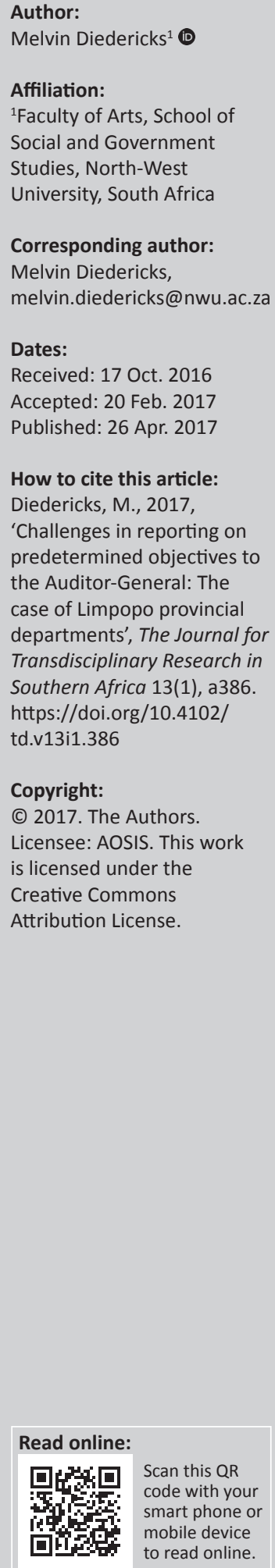

\begin{abstract}
Limpopo provincial departments like all other South African government departments are required to report on performance against predetermined objectives in terms of Section 40 of the Public Finance Management Act 1 of 1999, read in conjunction with Section 5.1.1 of the Treasury Regulations. The purpose of this article is to report on a study that was undertaken to establish the challenges faced by the Limpopo provincial departments in reporting on performance against predetermined objectives to the Auditor-General (AG). Reporting on predetermined objectives has been a challenge over the past financial years and this is evident in the AG's reports, in which Limpopo provincial departments continued to receive qualified audit reports. The literature review carried out for purposes of this study revealed that performance management is fundamental to enhancing organisational performance. A qualitative research design was used to collect and analyse data. Key findings of the study included that management should prioritise strategic planning, performance reporting, monitoring and evaluation to enable it to be in a position to make a determination as to whether what was planned by the department was actually realised. It is also of paramount importance that performance reporting is highly prioritised at strategic, tactical and operational management meetings to ensure more effective and efficient organisational performance.
\end{abstract}

\section{Introduction}

According to the National Treasury (2007a:1), performance information indicates how well an institution meets its aims and objectives, and which policies and processes are functioning effectively and contribute towards the achievement of organisational goals and objectives. Performance information is the key to effective management, including planning, budgeting and implementation, monitoring and reporting. Performance information also facilitates effective accountability, enabling legislators, members of the public and other interested parties to track progress, identify the scope for improvement and better understand the issues involved. Performance information is essential to focus the attention of public and oversight bodies on whether departments are delivering value for money by comparing their performance against their budgets and service delivery plans, and to alert managers to areas where corrective action is required. The most valuable reason for measuring performance is that what gets measured gets done (Osborne \& Gaebler 1992). This implies that 'if you do not measure results, you cannot tell success from failure; if you cannot see success, you cannot reward it; if you cannot reward success, you are probably rewarding failure; if you cannot see success, you cannot learn from it; if you cannot recognise failure, you cannot correct it; and if you cannot demonstrate results, you cannot win public support' (Halachmi 2002:65, 2005:503-504; Osborne \& Gaebler 1992). In other words, measuring performance has an impact on factors such as performance recognition, managing and correcting poor performance, as well as continuous organisational improvement.

This study was undertaken to, inter alia, determine and establish how Limpopo provincial government departments could effectively manage their performance by reporting accurately on predetermined objectives to the Auditor-General (AG). In order to achieve this research objective, the discussion in this article is organised into providing an overview of the research objectives of this study, a contextualisation of the South African governmental process with regard to performance information reporting, a thematic discussion of the empirical findings and recommendations with regard to the accomplishment of the research objectives. 


\section{Objectives of the study}

The study under discussion addresses the following research objectives:

- To investigate the nature, extent and challenges of reporting on predetermined objectives by Limpopo provincial departments.

- To provide recommendations and possible solutions on how to ensure proper reporting on predetermined objectives.

\section{Motivation for undertaking the study}

Currently, the AG performs the audit of predetermined objectives but does not express an audit opinion on the findings. The findings are reported as non-compliance matters because departments and municipalities are still struggling with accounting for their finances. Moreover, the non-reliability of performance information regressed from $54 \%$ in $2008 / 09$ to $77 \%$ in $2009 / 10$. This means that in 2008/09, only $46 \%$ of performance information could be relied upon, whereas in $2009 / 10$, the percentage dropped to $23 \%$.

The AG Report for 2008/09 (AG 2008) indicated that only 2 out of 12 Limpopo provincial departments would have received an unqualified audit of predetermined objectives if an opinion had been expressed (there are 12 provincial departments excluding the legislature and public entities). In the 2009/10 AG Report (AG 2009), only 4 out of 13 departments would have received unqualified audits, 4 would have received qualified audits, another 4 would have received disclaimers and 1 would have received an adverse opinion. In the 2010/11 report (AG 2010), only 7 out of 13 departments would have received an unqualified audit opinion, 3 would have received a qualified audit opinion, 1 would have received a disclaimer audit opinion and 2 would have received adverse audit opinions. Although the audit outcomes of Limpopo Province improved in the AG Report of 2014/2015, worrisome concerns remained and would have to be addressed (AG 2014:49). However, the AG Report 2015/2016 in comparison with the 2014/2015 AG Report found that the financial health of Limpopo provincial departments has regressed resulting in zero clean audits for 2015/2016 (ENCA 2016; Nel \& Erasmus 2016). Due to the aforementioned, the AG in Limpopo Province has placed more emphasis on the usefulness, accuracy, validity and reliability of the predetermined objectives in its annual report (AG 2014, 2015).

This study therefore sought to identify the challenges and bottlenecks faced by Limpopo provincial departments in reporting on performance in relation to objectives by inter alia analysing the Auditor-General Reports 2008-2015. It is through performance monitoring that one is able to determine whether or not the organisation is achieving its objectives. Improvement in reporting on predetermined objectives is therefore of paramount importance for more effective, efficient, economical and sustainable governance.

\section{Contextualising performance information reporting}

According to the UN (2002), reporting is the systematic and timely provision of essential information at periodic intervals. A performance report is a report on the performance of a predetermined activity. Such reports contain performance indicators, which measure the achievements of the organisation and its programmes. For example, for a police department the report might show the number of arrests, the number of convictions by crime category and the change in the crime rate (Schwartz \& Mayne 2005).

The purpose of performance information is to promote action. A good report should contain all the information necessary to facilitate decision-making at a strategic level. It should lead senior management to ask the right questions and initiate a chain of actions that will enhance the ability of the organisation to achieve its short-, medium- and longterm goals. Finance departments are particularly important in this context, because the information they provide reflects the overall health of an organisation. Thus, performance reporting has multiple audiences (Fourie \& Opperman 2010:258). Members of the legislature, the public, stakeholders and the media are all key audiences of performance reports in Limpopo Province. In addition, the organisation itself is an important user of performance reporting.

\section{The performance information reporting process in South Africa}

According to the Public Service Regulations (2001), the context for reporting on performance information in South Africa inter alia involves that after a general election, the ruling party identifies five key strategic priorities upon which it will focus. These priorities then cascade into medium-term strategic priorities that inform planning in the entire administration. The said administration should ensure that what is to be delivered by the departments ultimately contributes towards the achievement of these priorities. The Director-General of a province signs a performance agreement with the Premier that outlines the key priorities to be achieved. The members of the executive council (MECs) will also sign performance agreements with heads of departments, and key deliverables that will contribute towards achieving the key priorities will be enshrined in this agreement. The heads of departments will also sign performance agreements with senior managers in the department. These agreements will be linked to the strategic plan, as well as the annual performance plan (APP) of the department. These performance agreements are monitored quarterly through performance reviews or appraisals (SA 2001).

It is against this background that the Limpopo provincial government has the mandate to ensure that effective performance takes place across all of its provincial departments. The performance reports of provincial departments are subjected to auditing by the AG. Performance reporting arises from objectives that are determined by the 
provincial strategic plan and an APP. The former often indicates what will be achieved within a particular period with available resources.

Considering the above, it is important to note that when assessing performance information, issues of planning, and in particular strategic planning, performance management, adequate budgeting and reporting processes should be emphasised. This implies a linking relationship between planning, budgeting and reporting to be utilised by government departments in order to track and measure its performance, and to be held accountable. Performance information also needs to be available to managers at each stage of the planning, budgeting and reporting cycle so that they can adopt a results-based approach to managing service delivery (see Figure 1). The aforementioned planning, budgeting and reporting cycle is also referred to as the performance management process, and it emphasises planning and managing with a focus on desired results, and managing inputs and activities to achieve these results. Two frameworks issued by the National Treasury (2007a; 2007b) provide guidance to government departments on how to use this cycle, namely the Framework for Managing Programme Performance Information (FMPPI) published in 2007 and the Framework for Strategic Plans and Annual Performance (FSPAP) Plans published in 2010 (Van der Nest \& Erasmus 2011:140). The objectives of the FMPPI are to enable government departments to understand the importance of performance information as a management tool and how it is linked to the Government-wide Monitoring and Evaluation System (GWM\&E). The GWM\&E describes the Presidency's approach to performance management, monitoring and evaluation (The Presidency 2007, 2009). Furthermore, the FMPPI provides a clarification of the role of performance information in planning, budgeting and reporting. The second framework, the FSPAP provides the context on how to align strategic and annual performance planning with an emphasis on the outcomes-oriented monitoring and evaluation approach as articulated by the GWM\&E. The framework demonstrates that medium-term

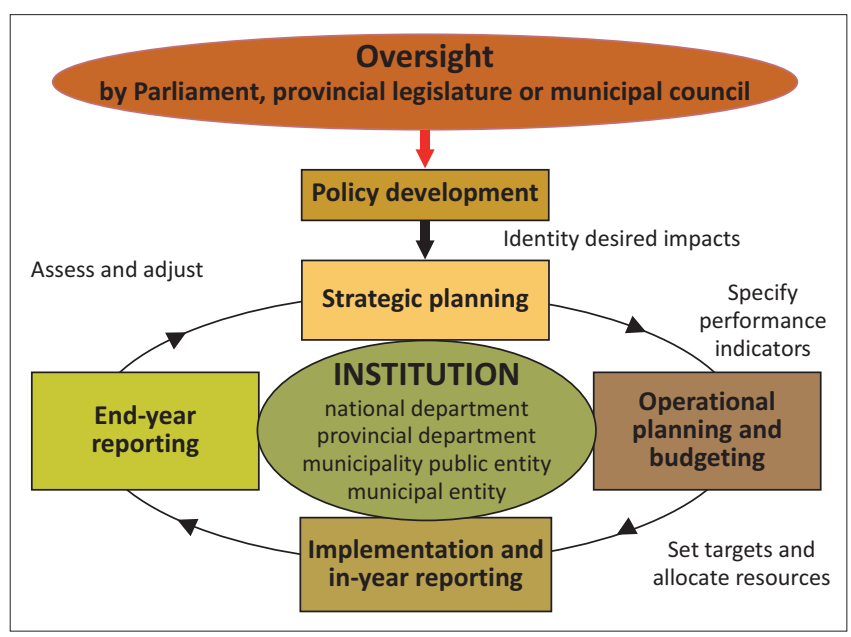

Source: National Treasury 2007b:4.

FIGURE 1: Planning, budgeting and reporting cycle. strategic plans and APPs can play a constructive role in clarifying the relationship between broader policies and programmes, and departmental or institutional budgets (National Treasury 2007b).

\section{Legislative and regulatory framework for performance information reporting}

Laws governing financial management in government departments and municipalities were enacted in 1999 and 2003. The overall specific objectives of financial regulation in South Africa are securing systemic stability in the economy, ensuring institutional safety and soundness, and promoting consumer protection (Falkena et al. 2001:2). Important legislative and regulatory requirements pertaining to performance information are subsequently discussed in order to contextualise compliance measures in place with which Limpopo provincial departments have to abide.

\section{Constitution of the Republic of South Africa, 1996}

The Constitution of the Republic of South Africa (1996) constitutes the immediate source of ethical directions to public officials in general and public human resources in particular. Section 195 (1)(b), Chapter 10 of the Constitution states that public administration must be governed by the democratic values and principles enshrined in the Constitution, including the following principles:

- A high standard of professional ethics must be promoted and maintained.

- Public administration must be development oriented.

- Public administration must be accountable.

- Transparency must be fostered by providing the public timely, accessible and accurate information (SA 1996).

Section 92 of the Constitution states that 'members of the Cabinet are accountable collectively and individually to Parliament for the exercise of their powers and the performance of their functions', and they must 'provide Parliament with full and regular reports concerning matters under their control'. Section 133 provides for the accountability of MECs of a province to the provincial legislature.

\section{Public Finance Management Act 1 of 1999}

Shall (2000:13) observes that the Public Finance Management Act (PFMA) emphasises the need for accountability of performance results by focusing on outputs and responsibilities, rather than just on procedural accountability, which ensures that rules have been adhered to. In other words, in terms of budgeting and financial management, the focus is not only on compliance with the relevant Appropriation Act but also on obtaining value for money from each government department for every rand spent.

The PFMA also introduced performance management into the public sector. In terms of the Act, the accounting officer 
must submit an annual report and audited financial statements that fairly present the state of affairs of the department, trading entity or constitutional institution, its business, its financial results, its performance against predetermined objectives and its financial position as at the end of the financial year concerned (SA 2000:50). Limpopo provincial departments are required in terms of Section 40(3)(a) of the Act to report on predetermined objectives at the end of a financial year. By doing so, those who are managing programmes are held accountable.

The importance of performance management and its appropriate application are further highlighted in that accountability for the effective, efficient and economical use of resources is not limited to the Treasury Department or accounting officers (the head of a department or the chief executive officer) but is also devolved to line managers who are accountable for their particular areas of responsibility. The aforementioned is detailed in Section 45 of the PFMA, which states that 'An official in a department - (b) is responsible for the effective, efficient, economical and transparent use of financial resources within that official's area of responsibility' (SA 1999). This implies that each line manager is responsible for the resources deployed in a particular programme and it is a requirement of Section 27(4) of the PFMA that measurable objectives must be submitted for each programme. Furthermore, line managers could also be held accountable for the outputs generated by a programme.

The PFMA gave rise to the Treasury Regulations 5 and 30, which mandate the accounting officer of an institution to establish procedures for quarterly reporting to the executive authority to facilitate effective performance monitoring, evaluation and corrective action. Reporting of quarterly performance will enable Limpopo departments to assess performance, that is, whether predetermined objectives have been met.

\section{Public Audit Act 25 of 2004}

The development of performance reporting is further enhanced by stipulations in the Public Audit Act 25 of 2004 that requires performance information to be subjected to auditing by the AG South Africa (SA). Section 4(1) (a) of the Public Audit Act provides that the AG must audit and report on the accounts, financial statements and financial management of all national and provincial state departments and administrations. The auditing of performance information provides assurance as to whether the reported performance against predetermined objectives produced by government institutions is useful and reliable (AG 2011:4; SA 2005).

Section 20(3) of the Act provides the AG with the discretion to report on whether the auditee's resources were procured economically and utilised effectively and efficiently. The Act also makes provision in Section 12(1) for the AG to authorise one or more persons to perform or to assist in the performance of an audit. The AG can therefore also authorise or undertake performance audits. Sections 20(1) and (2) of the Act further require the AGSA to provide an opinion or conclusion on the performance information reported against predetermined objectives. The importance of performance monitoring and reporting is also highlighted in the Public Service Regulations Act of 2001.

\section{Public Service Regulations Act of 2001}

The Public Service Regulations Act of 2001 provides a framework for strategic planning, performance management and monitoring. Part III B states that an executing authority shall prepare a strategic plan for the department. The plan should contain the department's core objectives, programme for achieving the objectives and how they will be monitored and measured. In addition, the plan should be linked with other government policies and regulatory mandates (SA 2001).

In terms of performance management and monitoring, Part VIII, A, B, and C of the Public Service Regulations Act 2001 stipulate that departments shall manage performance in a consultative, supportive and non-discriminatory manner, in order to enhance organisational effectiveness, efficiency and accountability for the use of resources in the achievement of results. The regulations further mandate departmental executive authorities to determine a system for performance management, development and monitoring of employees in a specific department (SA 2001).

The King Report on Corporate Governance illustrates the importance of reporting non-financial information and is therefore also noted as important legislation for the purposes of this study.

\section{King Code of Governance for South Africa}

The importance of integrated reporting, including financial and non-financial information, receives prominent attention in the King Code of Governance for South Africa, 2009 (King III 2009). The King III Report highlights the necessity of integrated reports to increase trust and confidence amongst stakeholders and provides legitimacy to the operations of an entity. The King Committee recommended integrated sustainability performance and reporting as a norm for business practices. 'Integrated reporting' refers to a holistic and integrated representation of a company's performance, in terms of both its finances and its sustainability. King III also applies to the public sector and recommends that entities should, by way of explanation, indicate whether the principles of the code have been applied or not (King Code of Governance for South Africa 2009:16). The King III Report further states that a province should appreciate that strategy, risk, performance and sustainability are inseparable (King Code of Governance for South Africa 2009:16).

Performance information reporting is also regulated in the local government sphere by the Local Government: Municipal Systems Act 32 of 2000 and the Local Government: Municipal Finance Management Act 56 of 2003. These Acts will, however, 
not be discussed, because the focus of this article is on provincial government departments. A concise overview of the research methodology and findings of this research is provided next.

\section{Research methodology and design}

A qualitative approach was used for this study because the data collected needed to provide insights and generalisations about Limpopo provincial departments. The fact that this study was contextual in nature and that it was aimed at arriving at an in-depth description and understanding of the challenges in reporting predetermined objectives to the AG meant a qualitative research approach was appropriate. Qualitative research methodology is concerned with understanding the processes and social and cultural contexts that underlie various behavioural patterns, and is mostly concerned with exploring the 'why' questions of the research. Qualitative research typically studies people or systems by interacting with and observing the participants in their natural environment (in situ), and focusing on their meanings and interpretations (Holloway \& Wheeler 1996).

The research design for this study, inter alia, included a study of the relevant literature and data collected through questionnaires and scientific analysis of the responses and interviews. The researchers adopted an interpretive social sciences approach by using a qualitative research design that is descriptive in nature. With qualitative research, it is important to also ensure triangulation. In this regard, data triangulation was ensured in this study by using multiple data collection methods such as a study of the relevant literature pertaining to performance information (theoretical overview), analysis of existing legislation, guidelines and protocols pertaining to performance information reporting, reviewing of Limpopo provincial departments official documents and obtaining data from interviews held with identified respondents. The primary research instrument used in this study was a questionnaire comprising both closed-ended and open-ended questions. The questionnaire provided the background to the study, but over and above the questionnaire, interviews were conducted with respondents. The closed-ended questions were categorised in a Likert scale formula, with scores ranging from one (1) to five (5), with one (1) being 'totally disagree' and five (5) being 'totally agree'.

The study was conducted in Limpopo provincial departments, which constituted the population for this study. Purposive sampling was used to target 36 participants for the survey, comprising of Chief Financial Officers (CFOs), planners and budget managers. The sample of 36 was based on the fact that there are 12 departments in the province (excluding the legislature and public entities), and in each department, three officials (i.e. CFO, budget manager and the planner) were purposively sampled to participate in the study. The 36 respondents were thus representative of the population, namely Limpopo provincial departments. Out of the 36 questionnaires that were distributed, only 30 were received back which amounted to $83 \%$ of participation in the study of those approached. Sixty-three per cent of the respondents were male, whereas only $37 \%$ were female. Forty per cent were CFOs, $27 \%$ were budget managers and $33 \%$ were planners. The data collected from the different respondents were analysed in order to arrive at an interpretation in relation to the entire population. The analysis and interpretation of empirical data are discussed according to relevant themes outlined in the next section.

\section{Research findings}

The empirical findings from the data obtained through a questionnaire and semi-structured interviews are described below. As alluded above, the performance information reporting process in South Africa focuses on the following key areas:

- Strategic planning and performance management processes.

- Performance reporting.

- Performance auditing.

- Monitoring and evaluation.

The above-mentioned key areas were utilised as themes to determine the extent to which measures have been put in place in order to report timeously, effectively and efficiently on predetermined objectives to the AG. Respondents were therefore probed by means of relevant statements to provide their opinion regarding the matter.

\section{Strategic planning and performance management processes}

This particular theme was tested amongst respondents by means of four separate questions aspiring to determine, firstly, whether top management gave strategic planning processes the attention they deserved; secondly, to determine whether APPs were developed in strategic planning sessions; thirdly, to observe whether targets in the APPs were thoroughly interrogated and whether they met the S.M.A.R.T (specific, measurable, achievable, realistic and time bound) criteria. Lastly, respondents were probed as to whether there was a link between strategic planning and the available budget of the department.

A well-functioning performance management process in government departments was emphasised earlier in this article, as it links planning to desired results, and managing of inputs and activities to achieve these results.

The majority of respondents $(60 \%)$ agreed that top management had prioritised strategic planning processes and that APPs were not merely a desk-top exercise but were developed in a strategic planning session. Targets in the APPs were, according to $70 \%$ of the respondents, thoroughly interrogated and adhered to the S.M.A.R.T. criteria. Only $50 \%$ were, however, of the opinion that there was indeed a link between strategic planning and the available budget of the department. 


\section{Performance reporting}

One of the recommendations of the AG SA to Limpopo provincial departments was that reports should be submitted timeously to the Treasury. This theme therefore firstly tested whether quarterly reports were submitted on time; secondly, if achieved targets were verified and submitted every quarter; and lastly, whether the available resources were provided by management to ensure that quarterly targets were achieved. As outlined above in this article, performance reporting should promote action as it contains performance indicators, which are important in measuring the achievements of the public organisation and its programmes.

The statistical results revealed that $80 \%$ of the respondents agreed with the first statement that quarterly reports are prepared and submitted to Treasury timeously. There was, however, still room for improvement, because $20 \%$ of the respondents were unsure or disagreed with the statement. Sixty-four per cent agreed that verification for achieved targets is submitted every quarter. Thirty-six per cent of the respondents who disagreed or were unsure about the statement raised eyebrows regarding the truth of the statement. Fifty-six per cent of the respondents were in agreement that the necessary resources were provided by management to ensure that quarterly reports were achieved. The $44 \%$ of respondents who did not agree or were unsure regarding the statement created doubt as to whether resources were in actual fact made available by management to ensure that quarterly reports were achieved.

\section{Performance auditing}

Performance information is subjected to auditing by the AG $\mathrm{SA}$, as alluded to earlier in this article. This specific theme therefore tested the level of understanding by officials as to how the AG defines accuracy, reliability and completeness of performance information. It is important for officials to have this understanding because this enables them to report performance information as required by the AG.

The statistical results revealed that $33 \%$ of the respondents disagreed with the statement, namely that there is a clear understanding of the AG's definition of accuracy, reliability and completeness of performance information by officials. Thirteen per cent totally disagreed with the statement. Because both respondents who disagreed and totally disagreed were in the majority, it could be deduced that there is a lack of understanding on how the AG defines accuracy, reliability and completeness of performance information.

Thirty-seven per cent of the respondents totally agreed or were unsure of the veracity of the statement.

\section{Monitoring and evaluation}

This theme firstly tried to determine whether quarterly reports submitted to Treasury were in fact analysed. It is important for Treasury to analyse performance reports submitted so that the gaps identified can be reported to the line departments. This gives departments the opportunity to correct performance reports before the audit by the AG SA. Secondly, the theme endeavoured to ascertain whether departments reviewed their performance quarterly. Quarterly reviews are important because this enables departments to monitor their achievements as per the APP.

Fifty per cent of the respondents were not sure whether Treasury analysed quarterly performance reports submitted and provided relevant feedback to departments in this regard. The statistical results revealed that the majority were unsure or disagreed with the statement. In this instance, it could be deduced that feedback is not provided on quarterly reports submitted to the Treasury by provincial departments.

Seventy-three per cent of the respondents agreed that quarterly performance review sessions were held in their respective departments, whereas $27 \%$ disagreed with the second statement of this theme. It can thus be deduced that quarterly reviews are held in departments to ensure that performance is reviewed.

Respondents were also confronted with open-ended questions requesting them to express their views with regard to how performance information is managed and reported in their departments, as well as how they perceived the Treasury and Office of the Premier in terms of providing support to achieve predetermined objectives. This is discussed in the subsequent section as confronting challenges.

\section{Challenges in reporting predetermined objectives}

Firstly, respondents were requested to indicate to what extent their strategic plan was linked to the budget and how problems relating to target setting could be linked to nonalignment of the two. All of the respondents (100\%) agreed that the strategic plan should be linked to the budget.

\section{However, challenges arise as a result of the following:}

- When budget cuts are implemented.

- The APP is finalised and submitted before the finalisation and tabling of the budget.

- There are instances in which the budget allocation is reduced or cut after the APP is submitted and this affects the targets as set out in the APP.

- Targets are not effectively costed per activity.

The above responses indicate that although all the respondents agreed that their strategic plans were linked to the budget, challenges arise when the budget allocations are reduced or cut. It would mean that some of the targets set before the cuts are implemented and might not be achieved. Targets in the APP are not based on activity-based costing $(\mathrm{ABC})$. $\mathrm{ABC}$ means that activities undertaken to support the achievement of the targets in the APP will be costed. 
Secondly, respondents were asked to indicate whether quarterly reports are submitted with means of verification (MoVs). This question was posed to determine whether MoVs are submitted to substantiate the targets achieved. All the respondents $(100 \%)$ confirmed that quarterly performance reports are submitted with MoVs; however, the following challenges were highlighted:

- In certain instances, MoVs are submitted after the due date.

- MoVs are merely submitted for the sake of compliance because the quality is poor.

- MoVs are not commensurate with the claimed achievement.

In light of the information provided by the respondents, it could be deduced that although MoVs are submitted, there is a level of non-compliance with the set submission dates and $\mathrm{MoVs}$ are not quality assured before submission.

In the third instance, respondents were asked to provide comment as to whether the quality of MoVs was reliable. The reliability of performance information gives an indication that the achievements are tangible. Ninety-four per cent of the respondents indicated that the MoVs were not of good quality. They indicated the following shortcomings:

- MoVs are submitted for compliance because the quality is not up to standard.

- The actual performance as reported does not address the target.

- Reports and MoVs were not in line with planned outputs as per operational plans, and standards set out in the policy framework were not adhered to.

It could therefore be deduced that although a portfolio of evidence regarding achieved targets is available, there is a shortcoming in terms of quality. The reporting of performance is not accurate because it does not address the target.

A fourth question posed to respondents was to provide comment on whether organisational performance review sessions were held in their departments. This question determined whether performance reporting is being taken seriously by departments. It is through this arrangement that departments can closely monitor their own performance. All respondents (100\%) indicated that they do have performance review sessions in their departments and this transpires due to senior management meetings being held quarterly.

The above responses indicate that performance review sessions are held within all relevant departments. It could therefore be deduced that departments continuously monitor their performance to ensure effective service delivery.

Respondents were also asked to describe the support they have received from the Office of the Premier and Treasury who are the custodians of planning, reporting, monitoring and evaluation. This question was posed to determine the level of support provided by the two departments to other sector departments. Ninety-five per cent of the respondents indicated that the support received was minimal. The respondents indicated as follows:

- The two departments are visible at the reporting stage but not necessarily during the planning stage.

- The two departments do not complement each other. Instead, they seem to be competing. Based on the above responses, it could be deduced that the two departments are not supporting sector departments, which is vital in terms of ensuring effective, efficient and economical reporting of performance information. This would also enhance the optimal functioning of the machinery of government.

In the last instance, respondents were asked to indicate if support from the Office of the Premier and Treasury was not satisfactory, what could have been the contributing factors. This question was posed to ascertain if there was a lack of support by the two departments. Eighty-five per cent of the respondents alluded to the fact that:

- There is lack of understanding of the business of client departments.

- The two departments lack capacity in terms of 'warm bodies' (human resources) to assist sector departments.

On the basis of the responses by the respondents, it could be deduced that the two departments are not able to live up to their expectations and there is therefore a need to build capacity in terms of both technical skills and adequate human capital.

\section{Discussion of findings}

The focus and purpose of this article was to determine the challenges in reporting on predetermined objectives to the AG SA by Limpopo provincial departments. The above-mentioned empirical findings demonstrated that respondents were of the view that ineffective performance reporting was still the order of the day, due to reasons such as the lack of technical and human skills, lack of sufficient support from both the Office of the Premier and Treasury, non-compliance with the set submission dates, MoVs that are not quality assured before submission and lack of understanding on how the AG defines accuracy, reliability and completeness of performance information. The research findings obtained from the questionnaires and interviews provided a picture of the status of how performance information is managed in provincial departments, especially Limpopo provincial departments, taking into consideration both the internal and external environment. A qualitative approach was adopted in order to achieve the set objectives of this study.

The observations were that, although Limpopo provincial departments have made significant progress in reporting performance information, it is evident from the analysis that performance reporting in departments is still not receiving the necessary attention it deserves. 


\section{Conclusion}

The study was motivated by reports of the AG that showed a lack of improvement in terms of the audit outcomes for predetermined objectives. Although there have been some improvements, there is still a lot to be done to improve the audit outcomes. The research revealed that Limpopo provincial departments faced serious challenges in reporting performance information. In addition, the literature review revealed that Limpopo provincial departments should focus more energy on planning, as this will ease performance reporting. Another revelation is that performance reporting ensures that those who are in charge of service delivery to the citizens are able to account for the resources utilised.

The following recommendations on how to improve reporting on predetermined objectives in Limpopo provincial departments are based on the extensive literature overview undertaken for the purposes of this study and the findings of the empirical study:

- Performance targets in the APP should be interrogated so that they meet the S.M.A.R.T. criteria.

- Limpopo provincial departments should develop policies, procedures and systems for managing programme performance reporting.

- Quarterly performance reports should be submitted with a portfolio of evidence (MoVs).

- A workshop should be conducted by the Office of the Auditor-General with officials in Limpopo provincial departments to establish a clear understanding of the AG's definition of accuracy, reliability and completeness of performance information by officials.

- There is a need to build capacity in the Limpopo Treasury and Office of the Premier, in terms of both the number of officials and the technical ability of those officials.

- The quality of the quarterly reports needs to be monitored in the same way as those done at the end of the financial year, and complete audit files prepared for each quarter. This will build up to the annual report that is to be audited by the AG. An electronic performance reporting system that can enforce timeous and complete reports should also be considered.

- The Limpopo Treasury and Office of the Premier should understand the business of each department so that proper guidance can be provided by the two departments.

Accordingly, future research should investigate the following:

(1) The role of Provincial Treasury and Office of the Premier as oversight institutions to enhance effective performance reporting.

(2) The impact of reporting predetermined objectives to Limpopo Province citizens.

\section{Competing interests}

The author declares that he has no financial or personal relationships which may have inappropriately influenced him in writing this article.

\section{References}

Auditor-General (AG) (South Africa), 2008, AG Report 2008/09: General report of the provincial audit outcomes of the Limpopo, Auditor-General's Office, Pretoria.

Auditor-General (AG) (South Africa), 2009, AG Report 2009/10: General report of the provincial audit outcomes of the Limpopo, Auditor-General's Office, Pretoria.

Auditor-General (AG) (South Africa), 2010, AG Report 2010/11: General report of the provincial audit outcomes of the Limpopo, Auditor-General's Office, Pretoria.

Auditor-General (AG) (South Africa), 2011, Your pocket guide to the audit of predetermined objectives, Auditor-General's Office, Pretoria.

Auditor-General (AG) (South Africa), 2012, AG Report 2012/13: General report of the provincial audit outcomes of the Limpopo, Auditor-General's Office, Pretoria.

Auditor-General (AG) (South Africa), 2013, AG Report 2013/14: General report of the provincial audit outcomes of the Limpopo, Auditor-General's Office, Pretoria.

Auditor-General (AG) (South Africa), 2015, AG Report 2014/2015: General report of the provincial audit outcomes of the Limpopo, Auditor-General's Office, Pretoria.

ENCA, 2016, Limpopo's financial health the worst in the country: AG report, 16 November, viewed 07 March 2017, from http://www.enca.com/south-africa/ limpopos-financial-health-the-worst-in-the-country-ag-report

Falkena, H., Bamber, R., Llewellyn, D. \& Store, T., 2001, Financial regulation in South Africa, SA Financial Sector Forum, Rivonia.

Fourie, M. \& Opperman, L., 2010, Municipal finance and accounting, Van Schaik, Pretoria.

Halachmi, A., 2002, 'Performance measurement and government productivity', Work Study 51(2), 63-73. https://doi.org/10.1108/00438020210418782

Halachmi, A., 2005, 'Performance measurement is only one way of managing performance', International Journal of Productivity and Performance Management 54(7), 502-516. https://doi.org/10.1108/17410400510622197

Holloway, I. \& Wheeler, S., 1996, Qualitative research for nurses, Blackwell Scientific, Oxford.

King Code of Governance for South Africa, 2009, King III, Institute of Directors in Southern Africa, Johannesburg, South Africa.

National Treasury (South Africa), 2007a, Framework for managing programme performance information, National Treasury, Pretoria.

National Treasury (South Africa), 2007b, Framework for strategic plans and annual performance plans, Government Printers, Pretoria.

Nel, Y. \& Erasmus, N., 2016, 'AG report: Limpopo slides backwards', Polokwane Observer, viewed 07 February 2017, from http://www.observer.co.za/ag-reportlimpopo-slides-backwards/

Osborne, D. \& Gaebler, T., 1992, Reinventing government: The five strategies for reinventing government, Penguin, New York.

Schwartz, R. \& Mayne, J., 2005, Quality matters, Transaction Publishers, New Brunswick, NJ.

Shall, A., 2000, 'The importance of the three E's in the budgeting process for line managers', IPFA Journal 1(3), 13-15.

South Africa (SA), 1996, Constitution of the Republic of South Africa, Government Printer, Pretoria.

South Africa (SA), 1999, Public Finance Management Act 1 of 1999, Government Printers, Pretoria.

South Africa (SA), 2000, Guide for accounting officers: Public Finance Management Act, National Treasury, Pretoria.

South Africa (SA), 2001, The Public Service Regulations, 2001, Government Printers, Pretoria.

South Africa (SA), 2005, Public Audit Act 25 of 2004, Government Printers, Pretoria.

The Presidency (South Africa), 2007, Policy framework for the government-wide monitoring and evaluation, Shereno Printers, Pretoria.

The Presidency (South Africa), 2009, Medium-term strategy fralmework: A framework to guide government's programme in the electoral mandate period (2009-2014), Government Printers, Pretoria.

United Nations, 2002, Handbook on monitoring and evaluating for results, United Nations Development Programme, Evaluation Office, New York, viewed 12 June 2011, from http://www.undp.org/evaluation/documents/HandBook/MEHandBook.pdf

Van der Nest, D.P. \& Erasmus, L.J., 2011, 'Reporting on performance against predetermined objectives: The case of South African National Government Departments', African Journal of Public Affairs 4(3), 135-151. 